\title{
PROTOTIPOS INTERPRETATIVOS, PRÁCTICAS DE APROPIACIÓN Y LUCHAS SIMBÓLICAS. REPLANTEANDO LAS RELACIONES ENTRE ESTOS TÉRMINOS A LA LUZ DE UN ESTUDIO EMPÍRICO SOBRE LA RECEPCIÓN DEL TANGO
}

\author{
INTERPRETATIVE PROTOTYPES, APPROPRIATION PRACTICES \\ AND SYMBOLIC STRUGGLES. RECONSIDERING THE \\ RELATIONSHIP BETWEEN THESE TERMS IN LIGHT OF AN \\ EMPIRICAL STUDY ON THE RECEPTION OF TANGO
}

\author{
María de los Ángeles MONTES \\ Instituto de Humanidades (UNC-CONICET) \\ montes.m.angeles@gmail.com
}

Resumen: Toda práctica de apropiación supone dos cosas: por una parte, se encuentra motivada por los intereses del agente social. Por la otra, supone a la interpretación como operación lógicamente anterior. Tan anterior se la concibe, que la semiótica cognitiva prescindió por completo del estudio de los usos de los signos. Sin embargo, creemos que existen razones para revisar el vínculo entre apropiación e interpretación, y la relación de esto último con los intereses de los intérpretes. Esta es la tesis que pretendemos desarrollar, que surge como resultado de un trabajo empírico sobre la recepción del tango por parte de milongueros.

Palabras clave: Recepción. Interpretación. Prototipos. Semiótica 
Cognitiva. Sociosemiótica.

Abstract: All appropriation practices suppose two things: on the one hand, it is motivated by the interests of the social agent. On the other, it assumes interpretation as a logical previous operation. This is so to such an extent that cognitive semiotics completely disregarded the study of the uses of signs. However, we believe that there are reasons to review the link between appropriation and interpretation, and the relationship of the latter with the interests of the interpreters. This is the thesis that we intend to develop, which arises as a result of an empirical work on the reception of tango by milongueros.

Key Words: Reception. Interpretation. Prototypes. Cognitive semiotic. Sociosemiotic.

\section{INTRODUCCIÓN: LA RECEPCIÓN MUSICAL VISTA DESDE UNA MIRADA SOCIOSEMIÓTICA}

Hablar de recepción, y más específicamente de recepción musical, nos enfrenta a un primer problema: delimitar lo que significa presentar un estudio en recepción. Por cuestiones de tradición disciplinar, los enfoques teóricos que sustentan las investigaciones sobre la recepción se han desarrollado en dos grandes direcciones. Por una parte, desde la sociología y los estudios antropológicos, la preocupación por lo que las personas hacen con los signos, como los usan, y los ponen al servicio de sus propias prácticas sociales, abrió una vía de investigación sobre las apropiaciones $^{1}$. Por la otra, desde la semiótica de raíz peirceana, se habilitó

\footnotetext{
${ }^{1}$ Entendemos signo en sentido amplio, no como unidad mínima de sentido, sino como cualquier cosa que es capaz de producir sentido como su efecto. Esto puede ser una palabra, un discurso, una música o una obra de teatro completa, en la medida en que es reconocida por alguien como una unidad significante.
} 
un interesante campo de investigación sobre la manera como la actividad interpretativa es la que permite, en última instancia, que estos objetos de la cultura tengan algún sentido. Con ese giro, la cuestión de la recepción de los signos ingresó también dentro de las preocupaciones de la semiótica.

Estas dos líneas de investigación, si bien coinciden en que el sentido es algo que, como mínimo, se completa en la instancia de la recepción, abordan problemas que deben ser diferenciados correctamente. Interpretar un signo y apropiarse de éste para intervenir en el espacio social, son ambas actividades productoras de sentido pero que ocupan momentos lógicos diferentes.

Interpretar correctamente un signo implica reconocer en lugar de qué objeto se encuentra ese signo (Eco, 1999: 146), atendiendo a las reglas interpretativas de la comunidad, y establecer la identidad de eso que interpretamos. Supone un esfuerzo cognitivo por determinar qué es o a qué clase de objetos pertenece (Violi, 2001). Apropiárselo, en cambio, supone siempre la interpretación y, a partir de allí, la presencia de un agente social productor de sentido que, realizando opciones en un marco de posibles discursivos (Díaz, 2013), produce prácticas significantes que impactan en su entorno social ${ }^{2}$.

${ }^{2}$ Si bien la distinción apropiación/interpretación tiene importantes puntos de parentesco
con la equiana uso/interpretación (Eco, 1987, 1992), difiere en que la comunidad que
sirve como garante intersubjetivo de la semiosis no es la comunidad de origen de la obra
sino la comunidad de intérpretes (Montes, 2011). Además, la noción de apropiación no
está aquí para distinguir la correcta interpretación de aquellas que serían aberrantes, sino
que posee valor analítico por sí misma. Nosotros coincidimos con Eco en la necesaria
separación de estas dos instancias, aunque nos distanciamos de su propuesta tanto en el
modo como traza ese límite, así como en el lugar que han de ocupar estos usos en nuestra
disciplina. En relación con la primera cuestión, Eco traza el límite con el concepto de in-
tentio operis, la cual vendría determinada por las normas interpretativas de la comunidad
de origen del texto (Eco, 1992:125). A nuestro entender esta manera de comprender las
cosas plantea problemas epistemológicos y teóricos. Por una parte, las reglas interpreta-
tivas de la comunidad de origen son, para muchos casos, imposibles de conocer y, por el
otro, representa una forma de fijar el sentido de manera estable y definitiva, idea que es
contraria a un espíritu peirceano. Pero, además, consideramos que los usos que se da a los
signos son un objeto de estudio de capital importancia para la semiótica porque implican
formas específicas de producción de sentido, pero también porque su estudio puede arro- 
Solo podemos apropiarnos de aquello que hemos reconocido previamente, de aquello que hemos evaluado, valorado y conjeturado en su sentido. Sin embargo, el modo como valoramos una música, por ejemplo, y el tipo de emociones que ésta es capaz de provocar como efectos de sentido, están fuertemente ligados al uso que le hemos dado a esa música en experiencias pasadas, lo que equivale a decir: al modo como nos la hemos apropiado anteriormente ${ }^{3}$. Ocurre que los hábitos y las competencias implicadas en la interpretación se adquieren, modifican o refuerzan en la experiencia, y las prácticas de apropiación forman parte de esa experiencia ${ }^{4}$.

No se trata solamente de que parte del reconocimiento de un determinado paquete significante incluye la identificación de cómo debe ser usado, lo que Gibson (2015) llama affordances y que López Cano (2011) denomina más específicamente affordances musicales, sino también la tesis complementaria: que lo que hacemos con él influye en cómo nuestra mente procesará eso que percibimos y, en última instancia,

jar luces sobre los procesos de formación, mantenimiento o modificación de los hábitos interpretativos.

${ }^{3}$ Por ejemplo, quienes bailan el tango de manera sostenida presentan unas competencias perceptivas que son específicas de esos consumidores de tango. Eso, sumado a la asociación afectiva entre esa música y las emociones producidas en experiencia de la danza, permite comprender por qué esos tangos que para el sentido común son tristes y melancólicos, para los milongueros son divertidos y alegres (Montes, 2014).

${ }^{4}$ Experiencia que puede ser directa o indirecta (a través de discursos). Kaliman y Chein (2014) distinguen entre la experiencia y el discurso como fuentes de esos saberes, aunque reconocen que esta distinción es solamente analítica ya que, en la práctica, nunca se dan de manera independiente. Existen casos extremos donde todo lo que sabemos, por ejemplo, sobre los "monstruos" o los "duendes", proviene de los discursos. Sin embargo, una vez puestas a rodar las palabras para darle sentido a la experiencia, esas experiencias le proveen de nuevas capas de sentido a las palabras. También Violi siguiendo a Brandt (2001: 325-331) reconoce distintas formas de experiencia (perceptiva, social y psicoemotiva). A pesar de lo productivos de esos debates, nosotros preferimos hablar de experiencia en sentido amplio, puesto que con esa noción apuntamos hacia el contacto pasado con esos signos que deja huellas en la psique bajo la forma de saberes. Aunque esas distinciones son importantes para una teoría general de las competencias semióticas, no lo son a los fines de este trabajo específico. 
lo que significará para nosotros en ocasiones posteriores.

Ahora bien, como expondremos en esta comunicación, muchas de esas prácticas de apropiación que tienen impacto en los procesos interpretativos futuros, están lejos de ser usos inocentes o desinteresados. Existen prácticas de apropiación que representan verdaderas apuestas, tomas de posición en relación con las disputas por la fijación del sentido.

Y, si seguimos el camino deductivo a partir de estas premisas, podemos suponer que esos intereses podrían tener algún tipo de impacto en el desarrollo de determinadas orientaciones interpretativas. Todavía más, que atender al estado de las luchas simbólicas (Bourdieu, 1995) de las que participan los sujetos involucrados en la recepción de los signos, y el lugar que ocupan los agentes en esas luchas, puede ser una clave para comprender por qué interpretan de una manera y no de otra.

En las próximas páginas desarrollaremos esta tesis, a partir de los resultados de una investigación empírica llevada adelante entre 2011 y 2014 dentro del circuito milonguero ${ }^{5}$ de la ciudad de Córdoba (R. Argentina), acerca de la recepción del tango argentino ${ }^{6}$.

Intentaremos mostrar cómo el análisis de las formas de apropiación en las que se implican los intérpretes, y el modo particular como éstos se involucran en las disputas sobre los modos legítimos de apropiarse del tango argentino, puede ayudarnos a comprender algunas diferencias en el modo como juzgan la pertenencia al género de distintas piezas musicales. Y que la definición de lo que es y de lo que no es un — verdadero- tango

\footnotetext{
${ }^{5}$ Milongueros/as es como se autodenominan los participantes de las milongas, los espacios donde se escucha y se baila el tango con fines sociales.

${ }^{6}$ En este trabajo nos limitaremos a dar cuenta de algunos aspectos de la recepción de la música del tango argentino, dejando por fuera otros aspectos como la recepción de la lírica o de la danza como espectáculo. Esta música la entendemos como un signo, como un paquete significante que, articulando elementos sonoros de diversa índole (rítmicos, melódicos, armónicos, etc.), es capaz de producir como primer efecto su reconocimiento como tal (como paquete y como significante). Un efecto que sólo puede producir en la interacción con un intérprete capaz de identificar cadencias, melodías, timbres, ritmos, affordances, etc, en base a sus competencias. Un signo que no deja de ser tal por no producir un significado en términos representacionales (López Cano, 2011).
} 
guarda vínculos, no necesariamente conscientes ni mecánicos, con los intereses de los agentes que se apropian de esas músicas.

\section{INTERPRETAR EL TANGO}

\subsection{La interpretación como proceso de categorización}

De los muchos interpretantes que puede producir una música, aquel que organiza a un conjunto de sonidos bajo la etiqueta de un género musical, es uno de los más interesantes.

¿Qué es un tango? No nos estamos preguntando en esta comunicación qué significa un tango particular, sino cómo se define lo que es un tango. Tampoco nos estamos preguntando cómo se define el género para los académicos ${ }^{7}$, lo que aquí nos importa es cómo los usuarios reales identifican un grupo de sonidos como un tango y no como un bolero, por ejemplo.

Reconocer un tango como tal y juzgar si ese tango es agradable o no, qué significa ese tango particular, qué emociones pretende comunicar, etc. son todas acciones que importan complejos procesos interpretativos. Estos no son otra cosa que procesos inferenciales, muchas veces tácitos o no conscientes, edificados sobre la base de competencias adquiridas en la vida en sociedad (CP 5.308). De modo que no hay nada natural en esos procesos, si por natural entendemos algo no socialmente producido ${ }^{8}$.

A la hora de apreciar una música debimos antes reconocerla como tal, y no como un mero conglomerado de sonidos desorganizados (ruido). Inmediatamente después la hemos asociado a otras músicas previamente

\footnotetext{
${ }^{7}$ Quien desee adentrarse en el debate desde la perspectiva de los académicos, puede recuperar el trabajo de Guerrero (2012) que sintetiza bien la forma como los musicólogos abordan el problema.

${ }^{8} \mathrm{Al}$ respecto puede consultarse el estimulante debate que mantuvieron Ramón Pelinsky (2005) y Rubén López Cano (2011), el primero sosteniendo una posición que podríamos llamar inmanentista en relación al sentido de la música, y el segundo sosteniendo una posición pragmatista, afín a la que asumimos en este trabajo.
} 
escuchadas y, con ello, a la valoración que hemos incorporado sobre esos géneros musicales ${ }^{9}$. Estos procesos, lejos de ser actos de identificación mecánicos, importan actos de categorización resultantes de procesos inferenciales apoyados en competencias previamente incorporadas ${ }^{10}$.

Quiere decir esto que para reconocer un tango como tango y no como otra cosa, por ejemplo, hemos seleccionado un género musical de entre los muchos disponibles en nuestros saberes para categorizarlo, y lo hemos hecho gracias a que hemos incorporado un Type (CP 4.537) que nos permite identificar a un determinado Token. Desde la perspectiva peirceana el Type es una categoría mental que permite determinar que el caso que se percibe pertenece a un grupo identitario o categoría. Compartimos con Violi (2001:154-212) la inclinación a entender los procesos de categorización desde las teorías de los prototipos.

Desde las teorías cognitivas clásicas un caso perceptible sería un Token de un determinado Type a condición de que presentase las características fundamentales que lo determinan (cual listado de rasgos necesarios). La teoría de los prototipos de Rosch (1978), en cambio, permite pensar que la pertenencia de un caso a una categoría es cuestión de grados, y que esto se determina en función de un juicio realizado por el intérprete sobre la similitud del caso (que sería el equivalente del Token peirceano) en relación a un prototipo en tanto ejemplo mejor ${ }^{11}$. Así, no

\footnotetext{
${ }^{9}$ La valoración es inseparable del acto de reconocimiento, porque viene adherida al objeto como su complemento predicativo. Por ejemplo, el reconocimiento de un "monstruo" como tal, incluye la valoración de éste como algo o bien feo, o bien aterrorizante (o ambas).

${ }^{10}$ Entendemos esas competencias en sentido amplio (Eco, 1992), como todos aquellos saberes - creencias- incorporados que permiten al intérprete realizar inferencias acerca del objeto que se le presenta. Saberes e inferencias no necesariamente conscientes que involucran al sujeto en cuerpo-mente y que "provee(n) de estrategias por medio de las cuales la mente musical instaura continuos cognitivos con los objetos musicales" (López Cano, 2004a).

${ }^{11}$ Decir que se funda en un juicio implica decir que no es un proceso mecánico ni de deducción simple. Por el contrario, se trata de una conjetura y como tal implica la puesta en juego de la creatividad del intérprete. Pasar de las condiciones necesarias y suficientes a los prototipos implica pasar de la deducción a la abducción, de los procesos que pueden
} 
habría solamente tangos y no tangos, sino también algunos que serían más tangos que otros, según el juicio elaborado por el intérprete ${ }^{12}$.

Ahora bien, ¿de dónde provienen estos prototipos interpretativos? Patrizia Violi (2001) sostiene que la fuente principal es la experiencia. Pero resulta evidente que las personas no poseemos los mismos recorridos experienciales y de allí que lo que para algunos es un mambo, para otros sea un boogie-woogie (López Cano, 2004b).

Estas diferencias no son solamente individuales. Aquello que es individual en los prototipos es mínimo en comparación con lo que tienen de intersubjetivo. Aunque es cierto que cada sujeto tiene un recorrido experiencial distinto y las competencias que adquiere son en algún punto siempre singulares, también es cierto que la vida en sociedad asegura un marco de intersubjetividad que garantiza la comunicación. Y mientras que lo singular interesa a la psicología, a nuestra disciplina le interesan aquellos aspectos que no lo son, puesto que revelan la existencia de terceridades (CP 2.148, 3.360).

Ahora bien, cuando la semiótica cognitiva (Paolucci, 2011, 2013) habla de la comunidad como garante intersubjetivo de la semiosis (Eco, 1992:369), generalmente está pensando esa comunidad en singular y en términos consensualistas ${ }^{13}$.

Se piensa en la comunidad, como si las complejas sociedades contemporáneas no estuvieran habitadas en su interior por distintas

\footnotetext{
ser llevados adelante por un computador a aquellos que sólo pueden ser hechos por seres humanos, de la decodificación a la creatividad, de la clausura del signo a su apertura.

${ }^{12}$ Que tendría puntos en común con lo que Eco (1999:152-226) denomina Tipo Cognitivo. No obstante, lo novedoso del concepto equiano es que introduce la distinción entre el Contenido Molar y Contenido Nuclear, distinción que, para nuestro caso, no resulta pertinente. Por este motivo preferimos mantener el concepto de prototipo.

${ }^{13} \mathrm{La}$ discusión sobre si lo que caracteriza a una unidad social es el consenso o el conflicto no ha sido explícitamente planteada en la semiótica interpretativa o cognitiva, como sí ha estado planteada en los debates de la semiótica rusa (Voloshinov, 1992) y de la sociología (Lorenzo Cadarso, 1995). Nosotros sostenemos que esta concepción de comunidad es consensualista por que la cuestión del conflicto ha estado simplemente ausente de los debates teóricos sobre la interpretación de los signos.
} 
etnias, tribus urbanas, generaciones y clases sociales, por mencionar sólo algunas de las fracciones sociales más clásicas. Se habla de la comunidad, como si los sujetos que la habitan no tuvieran intereses contrapuestos, no compitieran por la apropiación de recursos simbólicos socialmente valorados, no lucharan por imponer a los otros su propia visión del mundo, o sus propios marcos interpretativos.

Este es, a nuestro modo de ver, el aporte fundamental que puede hacer la mirada sociológica a la semiótica.

La comunidad debería ser sustituida, según entendemos nosotros, por las comunidades. Ya hemos mencionado cómo la de los milongueros, por ejemplo, desarrolla diferentes hábitos interpretativos en comparación con otros consumidores de tango. Pero, además, diferentes grupos de sujetos dentro del conjunto de los milongueros muestran divergencias significativas en sus juicios sobre lo que es, y lo que no es tango.

Proponemos renunciar entonces a cualquier idea de comunidad como todo cerrado y homogéneo, y reemplazarla por la de distintas subcomunidades cuya homogeneidad entre ellas, y al interior de cada una, es parcial y frágil. En las que las luchas simbólicas lejos de ser anomalías sistémicas, son la fuerza que dinamiza la cultura y promueve el cambio. Donde la perdurabilidad de esas comunidades se basa en la mutación lenta pero constante, y no en la inmutabilidad ${ }^{14}$.

\subsection{Lo que es el tango según ellos}

\subsubsection{El tango prototípico y sus características}

Mirando desde esta perspectiva la cuestión, nos preguntamos

\footnotetext{
${ }^{14}$ Creemos, además, que este postulado es consistente con el sinequismo peirceano, donde la continuidad infinita de la semiosis, por ejemplo, se da a condición de que en cada eslabón de la cadena haya un interpretante en lugar del signo anterior, otro signo distinto, en algún aspecto equivalente, pero siempre en algún punto diferente. Esto abre paso a la creatividad y al cambio en el continuum, no como anomalía sino como condición presupuesta.
} 
cuál era el tango prototípico para los milongueros, y cuáles eran sus características. Y, a partir de allí, cómo arribaban a juicios tales como “esto es un tangazo" o "esto no es tango". Y, todavía más importante, si era posible encontrar diferencias en esos prototipos entre distintos grupos de sujetos, o si podíamos ofrecer algún principio explicativo de esas diferencias.

Para hacerlo realizamos una rueda de entrevistas en las que preguntamos, en una primera instancia, sobre sus opciones personales: Cuáles tangos eran sus preferidos, por qué motivo, en qué versiones, etc. En un segundo momento citamos a los mismos entrevistados y les hicimos escuchar tangos, de diferentes estilos, y se les pidió que los valorasen y que dieran razones para esa valoración ${ }^{15}$.

Se hizo evidente que, para los milongueros, el tango prototípico era aquel perteneciente a las orquestas típicas de la llamada época de oro del tango ${ }^{16}$. Era algo previsible, dado que los tangos de esta época son los más escuchados por ellos en las milongas cordobesas y, como dijimos antes, los prototipos se forman en base a la experiencia. Ahora bien, dijimos que la pertenencia de un caso a una categoría es cuestión de grados, entonces la pregunta que nos hicimos fue: ¿cuánto distanciamiento se tolera y en qué dirección? Al preguntarnos esto nos estábamos preguntando acerca de dónde trazan los límites — difusos — del género y, eventualmente, cómo y por qué.

En concreto: conocer que el tango de orquesta típica de la época de oro es el tango prototípico nos permite comprender por qué todos los milongueros entrevistados juzgaron que "Canaro" en la versión de la

\footnotetext{
${ }^{15} \mathrm{La}$ selección de milongueros a entrevistar apuntó a construir una muestra teórica (Glasser y Strauss, 1967) que incluyó 26 milongueros de entre 22 y 65 años distribuidos de manera homogénea entre varones y mujeres, adherentes a diferentes paradigmas discursivos. Sobre la definición de esto último volveremos con más precisión en el tercer apartado. ${ }^{16}$ La llamada "época de oro" comprende los años entre 1930 y 1950 aproximadamente, momento en el que se registraron la mayor cantidad de producciones, coincidiendo también con la época de los grandes bailes de salón y la expansión del tango como música y baile popular (Pujol, 1999).
} 
Orquesta de Juan D'Arienzo es un tango, incluso por qué es para ellos un "tangazo", pero nada nos dice de por qué algunos consideraron que el tango electrónico sí es tango, mientras que otros juzgaron que no lo es. O por qué algunos expresaron que el que interpreta Julio Sosa es menos "verdaderamente" tango que el interpretado por Alberto Echagüe. Vale decir, por qué motivo unos juzgan a esas variantes como más o menos parecidas al prototipo que otros.

La cuestión la resolvimos indagando sobre las características de ese prototipo que los distintos grupos de milongueros juzgaban como más esenciales ${ }^{17}$.

Para abordar esa cuestión les ofrecimos casos concretos de diferentes estilos de tangos donde uno o varios elementos eran no coincidentes con el prototipo, y les pedimos su opinión sobre esas piezas, para luego preguntar en qué basaban esos juicios ${ }^{18}$.

A partir de allí, pudimos reconstruir al menos dos versiones diferentes de ese prototipo, según dónde colocaban los límites de lo que es y de lo que no es tango, y las zonas de frontera donde ubicaban casos que, sin dejar de pertenecer del todo a la categoría, tampoco eran considerados buenos ejemplares ${ }^{19}$. Aparecieron así al menos dos configuraciones distintas que eran compartidas por diferentes grupos de sujetos, según

\footnotetext{
${ }^{17}$ Patrizia Violi (2001: 218-238) sostiene que los prototipos poseen algunas características que serían esenciales y otras que serían típicas. En este trabajo nosotros diremos que existen elementos que el intérprete juzga como más esenciales que otros para recordar siempre que la pertenencia de un caso a la categoría es cuestión de grados, y que no hay nada verdaderamente esencial en estas características.

${ }^{18}$ Se les hizo escuchar "Suerte loca" (OT Enrique Rodríguez), "Canaro" (OT Juan D’Arienzo), "Adiós Nonino" (Piazzolla), "Lo han visto con otra" (OT Fervor de Buenos Aires), "En esta tarde gris" (OT Imperial), "Mano a mano" (Julio Sosa), y "Como dos extraños" (Adriana Varela). En todos los casos las preguntas no se limitaron a estos únicos casos, sino que, por el contrario, se utilizaron como disparador para sondear sus opiniones sobre éstos y otras variantes como por ejemplo las interpretaciones de Cacho Castaña y el moderno tango electrónico.

${ }^{19}$ En realidad, reconstruimos tres versiones, pero por cuestiones de extensión expondremos aquí únicamente dos. De todas formas, vale aclarar que las conclusiones que presentamos en este trabajo se desprenden del análisis de los tres casos.
} 
se puede observar en la figura 1. En esa imagen se pretende graficar de manera topográfica el grado de cercanía, en relación con el prototipo, de diferentes casos discutidos durante las entrevistas.

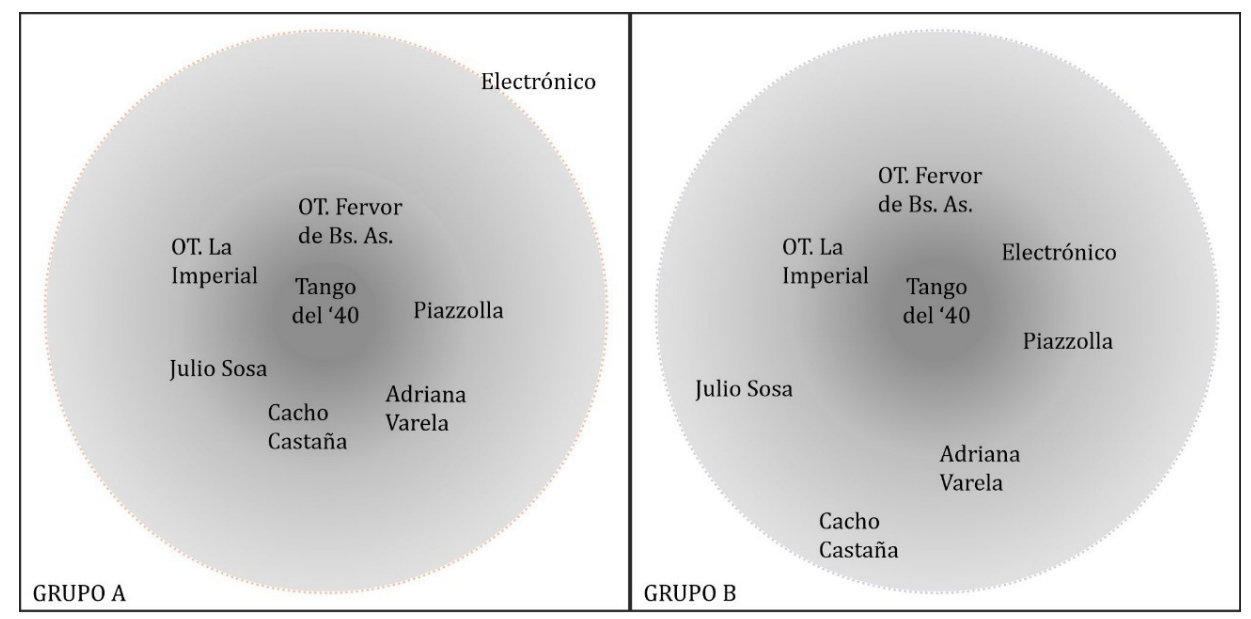

Figura 1. Representación topográfica de la distribución de casos en relación al prototipo.

\subsubsection{Claves para reconocer al verdadero tango argentino}

Para un primer grupo de milongueros (llamémoslo por el momento grupo A), de los ejemplos ofrecidos por el entrevistador, existe un solo caso que se encuentra claramente en las afueras del prototipo: el tango electrónico ${ }^{20}$. Es "demasiado moderno", decían los más cautos y "eso no es tango", los menos. Concretamente, significaba que esa música contenía elementos extraños: No son canciones compuestas en la época dorada del tango, no está interpretado por una orquesta típica, la base rítmica está diseñada por sintetizadores y no por los instrumentos tradicionales (piano, bandoneón, contrabajo), aparecen sonoridades extrañas (distorsiones, bajo

\footnotetext{
${ }^{20} \mathrm{Si}$ el tango electrónico es o no es realmente un tango, en términos formales, es algo que no debatiremos en esta comunicación. A los fines de nuestro trabajo importa que es un tipo de música que circula en el ámbito de algunas milongas, cual si fuera tango, y que para algunos milongueros forma parte del universo del tango.
} 
eléctrico, batería), la forma lírica no se corresponde a la del tango canción, y por todo esto la asociaban más al rock que al tango. Todavía más, lo percibían como una usurpación del género.

Otros rasgos que sí compartían con el prototipo — como la presencia de una fuerte marcación rítmica que permite el baile o la presencia dominante de la sonoridad del bandoneón-, no alcanzaban para que fuera incluido en la categoría.

No ocurría lo mismo con, por ejemplo, la pieza interpretada por Adriana Varela la cual, sin embargo, también contenía elementos que en principio parecían muy distantes del prototipo. Estaba interpretada por una voz femenina ${ }^{21}$, tenía sonoridades extrañas (la de un saxofón, por ejemplo) y se trata de una versión que se adapta mal a la danza del tango ${ }^{22}$. A pesar de esto, los entrevistados de este grupo juzgaron que sí se trataba de un tango, en una versión que a la mayoría no agradaba mucho, sin perjuicio de que por eso sea considerada perteneciente al género con total derecho. La clave de ese juicio estaba en el reconocimiento de que se trataba de una nueva versión, pero de un tango clásico. Así, en este caso, la operación cognitiva que realizaban consistía en separar por una parte la canción en sí (como si la canción poseyera una identidad que no es permeable a las variaciones que le imprimen los músicos), de los arreglos de la versión de Varela. Estos últimos elementos eran juzgados como menos importantes que el reconocimiento de la canción como perteneciente a lo que denominaremos un repertorio instituido del tango. Identificar la canción como perteneciente a ese repertorio resultaba para ellos un indicio fuerte de pertenencia al género. Ocurría algo similar con "En esta tarde gris", en la cual el reconocimiento de la canción como un tango perteneciente a este repertorio resultaba suficiente para que lo incluyeran en el género, a

\footnotetext{
${ }^{21}$ Aunque en los años 40 existieron cantantes mujeres, éstas no fueron más que excepcionales. Además, el modo de cantar y colocar la voz de esas cantantes mujeres es muy diferente al de Varela, cuya voz es más "masculina" (según evaluaron los entrevistados). 22Tiene una muy débil marcación rítmica lo cual dificulta al bailarín poder seguir el ritmo, y un tempo más lento de lo usual, haciendo que para caminar a ritmo los bailarines deban dar pasos mucho más amplios de lo acostumbrado.
} 
pesar de que no estaba interpretada por una orquesta de la época de oro. No obstante, en este caso, el reconocimiento de que se trataba de una orquesta típica la acercaba más al prototipo, en comparación con el caso de Varela.

Llamativo fue el caso de Adiós nonino, interpretado por el quinteto de Astor Piazzolla en la versión de 1961. No se trataba de una canción compuesta en la época de oro, ni estaba interpretada por una orquesta típica. A pesar de esto, los entrevistados de este grupo no dudaron en reconocer la pieza como un tango. Una vez más, para elaborar ese juicio se basaban en el conocimiento que tenían sobre este repertorio instituido, aunque en este caso formaba parte de un repertorio, según ellos, más "moderno" (y por eso valorado como menos prototípico). Todos identificaron que se trataba de un tango de Piazzolla, e incluso algunos identificaron el nombre de la pieza. $\mathrm{Al}$ igual que en el caso de Varela, reconocer la pieza como perteneciente a ese repertorio fue suficiente para juzgarla como perteneciente al género, aunque, en este caso, reconocían que no se ajustaba plenamente a lo que el tango es según ellos, no ya por las variaciones que le imprimieron los músicos, sino por su identidad. Vale decir, no porque los arreglos musicales hubieran desvirtuado la canción — como en los casos anteriores-, sino porque el tema en sí mismo sería menos prototípico. Y para avanzar ese juicio no apelaron a cuestiones de forma musical ni a tecnicismos musicológicos: el hecho de que la danza no fuera su forma de apropiación prototípica era el elemento clave para avanzar ese juicio.

Pertenece, según ellos, a una variante del género más estilizada, pero menos genuina. Aunque le reconocían valores tales como la complejidad estética, esta característica era para este grupo menos esencial. El tango, según ellos, era una música popular compleja (más compleja que la cumbia villera o el cuarteto cordobés), pero cuya affordance prototípica era la danza ${ }^{23}$. Y cuando esas dos características entraban en contradicción, la segunda resultaba más esencial.

\footnotetext{
${ }^{23}$ Sobre la función de distinción social que el consumo de tango juega en las narrativas identitarias de estos milongueros, puede consultarse un trabajo publicado con anterioridad (Montes, 2016).
} 
En resumen, podemos afirmar que, para este grupo de milongueros, aquellas características del prototipo que permitían afiliar el caso a un repertorio instituido resultaban siempre más determinantes que cualquiera de las otras.

Y si bien el reconocimiento de la melodía o de la letra de un tango clásico fue un rasgo fuerte de asociación al género en todos milongueros, sólo en este grupo esta característica se volvió tan determinante.

Al reconocimiento del repertorio le seguía, en orden de importancia, el reconocimiento del tipo de orquestación. Que no permitiese el baile era sólo aceptable si se trataba de una canción del repertorio instituido (sea clásico o piazzollano), en la medida en que consideraban que eso era algo dependiente de esa versión particular y que eso no modificaba la identidad de la canción (la cual seguía siendo para ellos un tango).

Para el segundo grupo (B), en cambio, ningún caso quedó completamente fuera de la categoría, aunque algunos quedaron en zona de frontera. Lo más destacado fue que el tango electrónico sí fue considerado un caso que aplicaba a la categoría en igual medida que, por ejemplo, el tango piazzollano, e incluso más que Adriana Varela o Cacho Castaña.

Tanto sobre el electrónico como sobre el tango piazzollano, los milongueros de este grupo destacaron su innovación y creatividad, y éstas como características asociados al tango como género. Sería, para ellos, una diferencia importante con otros géneros de música popular bailable, como el cuarteto cordobés o la cumbia villera. Para ellos, a diferencia del grupo anterior, que la pieza musical habilitara la apropiación a través de la danza del tango era importante, pero también era muy importante la cuestión de la "calidad" artística de la pieza.

En lo que respecta al tango electrónico, la hibridación y la innovación estética era para ellos un elemento valorado positivamente, como indicio de búsqueda artística y, por lo tanto, de calidad. De modo que otras características del tango prototípico pasaban a ser menos esenciales si se resignaban en favor de la innovación estética.

La articulación entre instrumentos reconocidos como pertenecientes 
al tango prototípico (bandoneón) con sonoridades ajenas a éste, lejos de operar como un rasgo que expulse el caso de la categoría como ocurría para el grupo anterior, era interpretada positivamente como signo de innovación.

Para ellos la presencia fuerte del bandoneón o las temáticas tangueras en las letras, asociadas a la rítmica que permite el baile del tango, resultaban suficientes para ligar la canción al género.

En cambio, las canciones de Julio Sosa, Cacho Castaña o Adriana Varela recibieron mayores cuestionamientos. En estos tres $\operatorname{casos}^{24}$, aunque no negaban la pertenencia al género (especialmente por el reconocimiento de ese repertorio instituido), juzgaban que el modo como versionaban estos tres cantantes esos tangos clásicos colocaba a estos casos en una zona de frontera. Reconocían que se trataba de tangos, pero los juzgaban menos "auténticamente" tangos.

Para ellos, a diferencia del grupo anterior, habría también elementos de la ejecución de los músicos y cantantes que serían características importantes del prototipo: una suerte de "autenticidad" en la selección de arreglos y en la vocalización.

En todos los casos se trataba de la presencia de rasgos que ellos percibían como indicios de impostación. Ese era el caso cuando los cantantes pretendían dar, según los milongueros, una imagen de "macho tanguero" o "gata arrabalera". Una performance que juzgaban exagerada y por eso mismo falsa, y que se materializaba en signos de diferente tipo: desde la vestimenta fuera de época o contexto, pasando por la gestualidad ${ }^{25}$, hasta alcanzar elementos más específicos como la colocación de la voz para cantar o la pronunciación ${ }^{26}$.

\footnotetext{
${ }^{24}$ En menor medida Adriana Varela, sobre la cual hubo menos consenso en las opiniones. ${ }^{25}$ Aunque en la entrevista se audicionaron las canciones sin imágenes ni vídeos, los milongueros, al reconocer a los intérpretes, introdujeron espontáneamente la discusión sobre la imagen que construían apelando a lo que conocían de ellos. Una cantante mujer que se viste "como prostituta", un cantante varón que "pone cara de macho cornudo" o que viste "como payaso".

${ }^{26}$ Según ellos exageraban el sufrimiento al cantar, o fingían una entonación demasiado
} 
A diferencia del grupo A, no se trata simplemente de que esa versión de la canción no fuera de su agrado, sino que esta diferencia afectaba su legitimidad como ejemplar de la categoría.

En algunos casos esa falta de autenticidad venía también acompañada de otras valoraciones negativas asociadas. En el caso de Cacho Castaña, en particular, fue recurrente la apreciación de que se trataba de un producto de baja calidad estética lo cual, como ellos lo entendían, implicaba una suerte de traición al género.

Hasta allí quedaba claro que, aunque coincidían en el prototipo de tango, los rasgos que consideraban más relevantes de ese prototipo no eran los mismos. Si seguimos el camino que nos plantea la teoría, deberíamos deducir la existencia de alguna diferencia significativa en la experiencia que esos dos grupos han tenido con el tango, a partir de la cual habrían desarrollado tan diferentes competencias interpretativas.

Y así era, efectivamente. Sin embargo, encontramos que las diferencias no provenían de que unos hubieran crecido escuchando tango electrónico y los otros no, por ejemplo ${ }^{27}$. Las diferencias parecían tener más que ver con los intereses que atraviesan sus prácticas de la apropiación.

Pero para desarrollar mejor esto dejaremos por el momento la cuestión del género y de sus tokens. En el siguiente apartado abordaremos una cuestión en apariencia desvinculada del tema, prometiéndole al lector que más adelante las conexiones se harán evidentes.

porteña, o carraspeaban demasiado la voz (en el caso de Adriana Varela). En el caso particular de Varela, no obstante, se comprobaron algunas excepciones. Algunas milongueras destacaron esa masculinidad de su voz como un elemento transgresor y, por lo tanto, valorado.

${ }^{27} \mathrm{De}$ hecho, lo que caracteriza a los milongueros cordobeses es que el tango no era una música escuchada por ellos antes de ingresar al ambiente de las milongas. En su mayoría, ellos se acercaron a la música del tango siendo ya adultos a través del interés por la danza y, luego, comenzaron a disfrutar de la música. 


\section{APROPIARSE DEL TANGO}

\subsection{Cuando la recepción también importa formas de apropiación}

Las prácticas de recepción no se limitan al plano interno del sujeto. Las personas hacen cosas con los signos, los usan, y al hacerlo los ponen al servicio de sus intereses. Sin embargo, no cualquier forma de apropiación es posible, ni igualmente válida.

De las muchas cosas que podríamos hacer con el tango, según estos milongueros la danza del tango sería la forma de apropiación más adecuada. Como ellos lo perciben, esa sería su "función" prototípica, su affordance.

No es casual, entonces, que el tango prototípico sea para ellos una música con fuerte marcación rítmica, un tempo que se adapta a las necesidades de la danza, y arreglos musicales que facilitan la percepción de esos elementos. Así, la música del tango más "auténticamente" tango según ellos, sería aquella que prescribe a la danza — que ellos practicancomo el modo de apropiación más legítimo y, de esta manera, a ellos mismos como los usuarios más adecuados ${ }^{28}$.

Pero, para que esto sea posible, una serie de creencias en torno a la naturaleza del tango los ayudan a construir un relato que justifica que ese, y no otro, sea el tango por excelencia y que esa, y no otra, la forma de apropiación más legítima. Y van todavía más lejos, les permiten trazar distinciones entre ellos postulando unas formas de bailar el tango, como más adecuadas que otras.

Pero para comprender cabalmente lo que viene a continuación debemos antes decir algo acerca de las milongas y de los milongueros. Las milongas son espacios sociales donde los agentes se vinculan en función de un interés común, de una illusio (Bourdieu, 1995: 79-81), que en este caso gira alrededor de la práctica de la danza del tango y de actividades

\footnotetext{
${ }^{28}$ Esto se relaciona con las disputas que entablan con otros consumidores de tango, especialmente músicos y críticos (Montes, 2016).
} 
relacionadas con esa apropiación. Vale decir, esa forma de apropiación involucra un interés particular para ellos. Ser un buen bailarín/a de tango otorga prestigio, admiración de los pares, mejores oportunidades de encontrar pareja sexual o amorosa, e incluso mejores posibilidades a la hora de entablar vínculos amicales. Es por este motivo que resulta tan importante analizar cuáles son los modos considerados correctos de encarnar el tango y, todavía más, deseables. Y al decir encarnado, nos referimos al modo como el tango se traduce en cuerpos que visten, bailan y circulan en el espacio de las milongas.

Como ellos lo entienden existirían modos adecuados e inadecuados de ponerle cuerpo al tango, como si fuera el propio tango el que dicta esas reglas. Y tan importante es esto que mantienen fuertes disputas por establecer esos límites.

Y aquí queremos introducir una cuestión muchas veces olvidada en los enfoques puramente cognitivos: No todo el mundo dispone de las mismas competencias o recursos para interpretar e, incluso, apropiarse de igual manera de los signos ¿Qué ocurre si el modo socialmente más valorado de apropiarse del tango supone recursos (competencias o propiedades) que sólo algunos poseen? A diferencia de los enfoques puramente semióticos, nosotros entendemos que las competencias de los usuarios de los signos no sólo sirven para comprender el sentido, sino que también son fuente de una capacidad diferenciada de relación (Díaz, 2011). Así las competencias se convierten, también, en recursos eficientes (Costa y Mozejko, 2002), en fuente de poder.

Saber bailar y hacerlo "bien", reconocer elementos raros de las melodías y saber utilizarlos a la hora de bailar, saber y poder vestirse de manera "acorde", saber y poder moverse "en tiempo", saber escuchar "las corcheas", tener "musicalidad" para bailar, tener "plasticidad" para moverse, etc., son competencias que pueden ubicar a quienes las poseen en un lugar social diferente de quienes no.

Allí es donde la cuestión del poder se entreteje con las preocupaciones por la recepción, y habilita interrogantes acerca de las estrategias que 
ponen en acción los agentes para mejorar o mantener su posición ${ }^{29}$.

Estas estrategias las podemos reunir en dos grandes grupos: Por una parte, la adquisición de más y mejores recursos, entendiendo por recursos cualquier propiedad, atributo, competencia física, perceptiva o cognitiva, que permita a los milongueros marcar diferencias positivas en relación a otros milongueros. Por la otra, la disputa por la adjudicación de valor relativo a los recursos existentes.

Y los milongueros, en general, hacen ambas. En la figura 2 resumimos los recursos más importantes en el ambiente milonguero al momento de la realización de esta investigación.

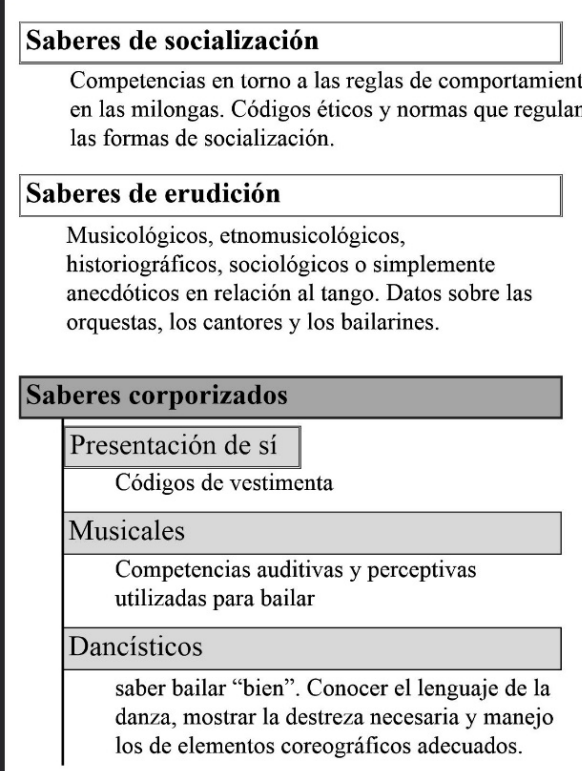

\section{Gestión de vínculos amicales y solidarios \\ Asistencia frecuente a lecciones, prácticas de tango y milongas, manteniendo así los vínculos con potenciale compañeros/as de baile.
Ser "profesor/a" de tango
Dictar clases, cursos y seminarios. Tener muchos alumnos y ser reconocido/admirado por los noveles bailarines. Permite además ser formador en lo que respecta a códigos y normas de apropiación dentro de las milongas.

\section{Gestión de espacios \\ Gestión de Milongas, de "prácticas" y de espacios donde se imparten clases de tango. Participación como DJ de milongas, de publicaciones sobre tango (espacios de ateneo, programas de radio, etc.)}

\section{Trayectoria en el campo Reconocimiento por ser un "viejo milonguero" \\ Atractivo físico / belleza \\ Adecaución a los cánones de belleza. Recurso que} adquiere más valor en las mujeres que en los varones.

Figura 2. Recursos más eficientes dentro del circuito milonguero

Se hace evidente que no todos esos recursos son igualmente adquiribles, ni los son de igual modo para cualquiera ${ }^{30}$. Las características

\footnotetext{
${ }^{29}$ Porque las reglas preceden a los sujetos y son un condicionante objetivo de sus prácticas sociales, pero eso no impide que ellos puedan intervenir para modificarlas. Es por esto que preferimos hablar de agente antes que de sujetos.

${ }^{30}$ Esta es la razón principal por la que preferimos hablar de recursos eficientes y no directamente de capitales (Bourdieu, 1995:66). Se trata de recursos que, a la larga y merced
} 
físicas que hacen que una persona sea considerada por otras como bella o atractiva no son igualmente adquiribles como, por ejemplo, los saberes de erudición. Entre aquellos imposibles de adquirir y aquellos más fácilmente adquiribles, hay un largo continuum que varía de recurso a recurso, y de persona a persona.

Los saberes ligados al cuerpo, a las competencias dancísticas, por ejemplo, son más fácilmente adquiribles por los más jóvenes que por los adultos mayores y, contrariamente, el vestuario "elegante" suele estar más a disposición del guardarropa y del habitus (Bourdieu, 1991) de los adultos de edad avanzada que de los jóvenes.

Y eso explica por qué eran tan encendidos los debates entre los distintos paradigmas discursivos que habitaban el ambiente milonguero. Los paradigmas discursivos son normas que fijan lo decible, lo valioso, los usos correctos o incorrectos, bellos o desagradables, deseables o reprobables (Costa y Mozejko, 2007; Díaz, 2009). Así, el significado de "bailar bien" variaba de un paradigma a otro y, con eso, se modificaba también la eficiencia de los recursos que disponían (o no) los distintos milongueros.

\subsection{Dos variantes del ser tanguero}

Al momento de realizar este estudio, existían en el circuito milonguero cordobés al menos dos versiones en lo que respecta a los modos considerados correctos (e incorrectos) de corporizar el tango los cuales habitaban distintos espacios. Así, existían milongas en las que un paradigma discursivo era hegemónico y otras donde el hegemónico era otro paradigma discursivo. Diferentes conjuntos de normas que prescribían cómo debía bailarse el tango, cómo debían vestir esos cuerpos, cómo debían moverse y qué lugar social debían ocupar con arreglo a los recursos

a la gestión que hacen los propios agentes, pueden (o no) traducirse en alguna forma de capital simbólico, cultural o social, pero que no todos pueden ni adquirirse, ni acumularse cual capitales. 
que cada uno disponía para poder amoldarse a esos mandatos. Normas que habitaban diferentes milongas según se tratase de milongas tradicionales o relajadas ${ }^{31}$.

Y cada uno de esos paradigmas discursivos justificaba esas normas dando un contenido diferente a lo que significa bailar o vestir "bien" el tango, de manera tal que los recursos de cada milonguero eran más o menos eficientes según en qué milonga se encontrara, y con qué grupo de milongueros se relacionara.

Esas normas venían fundamentadas en un conjunto de creencias acerca de lo que "el Tango" significa, de su sentido y su naturaleza ${ }^{32}$. "El Tango" designa para ellos a una suerte de objeto cultural mayor, altamente valorado, que incluiría como componentes centrales tanto a la música como a la danza. El Tango tendría, como ellos lo entienden, un sentido y ciertos valores con arreglo a los cuales deberían definirse tanto la música como su danza. Las normas que regulan tanto las prácticas de apropiación como el valor de los recursos puestos en juego en esas prácticas aparecían así ocultando su arbitrariedad, presentándose como motivados por el Tango.

Para el paradigma tradicional el Tango era un legado cultural amenazado por la modernización. Un legado que tendría una esencia invariante, proveniente de un pasado idealizado, una tradición selectiva $a^{33}$, cuya génesis encontramos geográficamente en Buenos Aires y

\footnotetext{
${ }^{31} \mathrm{Y}$ también las neotradicionales, pero por cuestiones de espacio, como dijimos anteriormente, desarrollaremos solamente dos. El análisis detallado de estos tres paradigmas discursivos se encuentra para consulta del lector en trabajos antecedentes (Montes, 2015). Retomaremos en este parágrafo solamente aquellos elementos que resultan pertinentes para abordar las diferencias interpretativas. Las milongas cordobesas que denominamos tradicionales y relajadas tienen importantes puntos en común con las que en Buenos Aires, Carozzi (2011) denomina de esa manera.

${ }^{32}$ Es importante notar que, como ellos lo entienden, tanto la música como la danza formarían parte de algo más grande, una suerte de unidad cultural mayor llamada "el Tango", que tendría un sentido y ciertos valores comunes con arreglo a los cuales deberían definirse tanto la música como su apropiación. Para referirnos a esta concepción de los milongueros y distinguirla de la música reservaremos la palabra con mayúscula acompañada por el artículo en singular.

${ }^{33}$ Resultante de procesos intencionales de selección de elementos de un pasado, porque
} 
temporalmente en la época de oro. Según esta versión de lo que el Tango es, en ese momento fundacional se habrían acuñado ciertos valores, una forma musical, un estilo de baile específico, y unos códigos de comportamiento cuya no observación subvertiría esa esencia.

La elegancia de los bailarines se prescribía como el valor máximo de la danza, y esa elegancia se traducía en un estilo de baile de escasa traslación, pocas figuras y utilización de pocos recursos musicales. Un estilo de baile sobrio, no demasiado complejo ni sobrecargado de elementos, cognitiva y físicamente poco exigente. Por esta razón era un estilo de baile al alcance de los adultos mayores. Es más, al prescribir un estilo sobrio y no recargado de figuras, proscribía otras formas de bailar más recargadas, más complejas y, claramente, fuera del alcance de los viejos milongueros — como suelen llamarse—, aquellas donde podrían tener ventaja los más jóvenes.

No era de extrañar, entonces, que los que adherían a este paradigma fueran milongueros de entre 45 y 65 años de edad.

En la vereda opuesta se encontraban las milongas relajadas.

Desde la perspectiva del paradigma relajado el Tango no posee una esencia invariante, sino que muta constantemente adaptándose a los nuevos milongueros. Esa sería su naturaleza, y por eso el verdadero peligro para el Tango lo constituían esas normas rígidas y pasadas de moda que alejaban a los más jóvenes. El cambio no era visto como una amenaza sino como la evolución necesaria. Por este motivo el estilo de baile más adecuado era aquel más moderno, y el imperativo era que fuera divertido y creativo, antes que elegante. La creatividad era para ellos altamente valorada, como si de una característica esencial se tratase.

Esa creatividad venía dada, según ellos, por la combinación de muchos y muy variados recursos coreográficos y musicales. La complejidad coreográfica era un valor, al igual que la dificultad de ejecución. Lo mismo ocurría con la presentación de sí, donde se prescribía una vestimenta moderna, lo que coincidía con el modo de vestir normal de los adultos

resultan operativos para las disputas del presente (Williams, 1980). 
jóvenes de la ciudad.

No era de extrañar, por todo esto, que el paradigma relajado estuviera más extendido entre los milongueros y milongueras de entre 25 y 45 años, aquellos para los cuales la adquisición de competencias dancísticas complejas era comparativamente más accesible. A los jóvenes milongueros que vestían "como muñeco de torta" —utilizando traje y camisa los varones o vestido para coctel en el caso de las mujeres-, los percibían como impostores. En esas milongas, la vestimenta demasiado diferente a la que utilizan en otros ámbitos era percibida como una actuación, una falsificación de sí, que arrojaba a quien la luciese a hostil lugar del ridículo ${ }^{34}$.

En el cuadro 1 se presenta una comparación esquemática las creencias en torno a la naturaleza del tango con las que cada uno de esos paradigmas discursivos pretendían justificar la diferencial asignación de valor sobre los distintos recursos y, en el cuadro 2 , el contenido y valor que tenían estos últimos.

\footnotetext{
${ }^{34}$ Es por este motivo que nosotros pensamos estos espacios en términos de paradigmas discursivos, y no como inocentes lugares donde las normas (tradicionales) se relajarían. La supuesta mayor libertad que pregonan los asistentes a estas milongas oculta y naturaliza reglas de generación de prácticas y discursos tan coercitivas y normativas como las que habitan las milongas tradicionales. En el preciso momento en que niegan o flexibilizan unas normas, están instalando otras.
} 


\section{TRADICIONAL}

"El Tango" TIENE una esencia y esa esencia se encuentra amenazada

Esa esencia encuentra su origen y legitimidad en la época dorada (tradición selectiva)

Ese peligro proviene de la hibridación con elementos que tienen otros orígenes (tango escénico, técnicas de danza clásica, contemporánea, etc.)

Esa tradición impone también códigos de "respeto" a la trayectoria de los bailarines

La "auténtica" danza de los años dorados es elegante.

Esa elegancia proviene del abrazo cerrado, el porte, la sobriedad coreográfica y la vestimenta.

\section{RELAJADO}

"El Tango" NO tiene una esencia, no es inmutable. Es cambiante, modernizable, DEBE adaptarse a los milongueros de cada época

La única amenaza la representan las actitudes arqueologizantes que pretenden "rescatar" cosas que ya no existen, emular personajes del pasado (no autenticidad)

"El Tango" es lo que hacen (ellos) con él. Debe servir para disfrutar, conectar a las personas

La danza valiosa es aquella que expresa la creatividad de los bailarines

Esa creatividad proviene de la utilización de recursos musicales y coreográficos de dificil adquisición, combinación y/o ejecución.

Cuadro 1. Creencias en torno a la naturaleza de "El Tango"

TRADICIONAL

Saberes y recursos para

la presentación de sí.

Musicales

Dancísticos

\section{Vestimenta "elegante"}

Reconocimiento y distinción de valses, tangos y milongas. Reconocimiento de ritmo y melodía, utilización en la danza de tiempos fuertes y, ocasionalmente, tiempos débiles.

Estilo "milonguero".

Valores asociados a ese estilo: Elegancia (porte, vestimenta, sobriedad, "aplomo" para bailar)

baile fisica y cognitivamente menos exigente.

\section{RELAJADO}

Vestimenta moderna y "actual"

Reconocimiento y distinción de valses, tangos y milongas. Reconocimiento de ritmo y melodía. Utilización en la danza de tiempos fuertes y débiles. En menor medida, algunos utilizan también fracciones de pulso y elementos de la línea melódica.

Estilo "nuevoso".

Valores asociados: Diversión, juego y creatividad. Agilidad.

(adrenalina como premisa. utilización de muchas figuras y recursos coreográficos de gran dificultad de ejecucion, velocidad en el desplazamiento y cambios bruscos de dirección)

Baile física y cognitivamente muy exigente, que requiere cuerpos ágiles y jóvenes.

Cuadro 2. Recursos valorados según cada paradigma discursivo 


\section{CONSIDERACIONES FINALES}

\subsection{Atando cabos}

Tenemos entonces un grupo particular de consumidores de tango: los milongueros. Este grupo es especial porque funciona como una micro comunidad que define y disputa sus propias reglas de apropiación. Un grupo que se caracteriza porque hace de esa apropiación del tango el eje alrededor del cual gira su juego social.

Dijimos que todos ellos comparten el mismo prototipo de tango para juzgar la pertenencia de distintas piezas musicales al género. Todos ellos coincidieron en que el tango más "auténticamente" tango es aquel perteneciente a la época dorada. De las piezas musicales tratadas durante las entrevistas, Los tangos ejecutados por la Orquesta de Enrique Rodríguez y la de Juan D'Arienzo eran, en todos los casos, los que más se acercaban a ese prototipo. Y cualquier pieza que fuera similar a éstas, especialmente si se encontraba interpretada por una orquesta típica, era juzgada como un tango. Sin embargo, hemos visto que a la hora de juzgar piezas musicales con diferencias más marcadas en relación a ese prototipo, los consensos se diluían.

El problema reside en que no todas las características que posee ese prototipo fueron juzgadas igualmente importantes por todos los milongueros y eso se hacía evidente al momento de evaluar casos menos prototípicos. Esos casos representaban un desafío de categorización puesto que los obligaron a tomar decisiones sobre qué elementos dar prioridad, y para hacerlo debieron recurrir a otros saberes que le permitieran hacer esas inferencias.

Existía un grupo para el cual el principal rasgo que utilizaron como marcador de tópico en esos casos, fue la pertenencia de la canción a un repertorio instituido. Una suerte de registro mental de canciones que sí serían tangos, independientemente de las variaciones que pudieran imprimirle los músicos o arregladores, aunque las hicieran menos 
prototípicas. En cambio, el tango electrónico era fuertemente rechazado porque, precisamente, no pertenecía a ese repertorio.

En este punto resulta pertinente destacar que este mismo grupo de milongueros es el que, en materia de reglas de apropiación, adscribe al paradigma tradicional.

Ellos creen que el Tango es un bien cultural valioso cuya esencia se encuentra actualmente amenazada por la modernización. Una esencia inalterable, fija y clausurada, como el repertorio que han incorporado como herramienta de categorización. No se trata, a nuestro entender, de una simple coincidencia. Se trata de una correspondencia. No parece ser casual que sean ellos, justamente ellos, los más severos con el tango electrónico. Una variante que, además, asocian directamente a ese otro grupo de milongueros con el que se encuentran en directa competencia por espacios de legitimidad ${ }^{35}$.

Que sean ellos los que creen que las canciones de ese repertorio tienen una suerte de esencia tanguera que se mantiene inalterada aún ante los más extraños arreglos e interpretaciones. Que sean aquellos que juzgan las hibridaciones en la danza como algo peligroso, los mismos que entienden que el tango electrónico es "demasiado moderno". Los que piensan que el Tango es algo inmutable, son los mismos que creen en la existencia de un repertorio finito de canciones que habrían sido producidas en un pasado idealizado, el mismo del que creen que proviene la danza que ellos practican.

Una correspondencia análoga encontramos en el segundo grupo, que coincide con aquellos que adhieren al paradigma relajado. Los mismos que juzgaban al tango electrónico como tango con el mismo derecho que Piazzolla o cualquier orquesta moderna, son los que creen que el Tango es

\footnotetext{
${ }^{35}$ Y la asociación no es descabellada. Como señala Liska (2016), esas músicas rápidamente fueron acogidas por bailarines y maestros interesados en nuevas formas de exploración corporal y ruptura, lo que dio lugar a que esas nuevas corporalidades y estas nuevas músicas fueran quedando asociadas de modo tal que, en nuestro caso, algunos de los entrevistados referían a estos estilos de baile como "baile electrónico". Así es fácil entender que los cuestionamientos hacia la música se trasladan, casi por contigüidad, a los bailarines.
} 
un universo cultural actualizable, sin esencias fijas y en constante cambio. Aquellos que destacaban la "calidad" y la "innovación" como valor en la música del tango hacían lo mismo en relación a la danza (oponiéndola a la repetición y la tradición). Los que daban valor a la complejidad coreográfica eran los mismos que daban valor a la complejidad musical, y los que desvalorizaban el estilo de baile más simple que practicaban los tradicionalistas.

Los que cuestionaban a sus pares milongueros que utilizaban vestimentas fuera de época y seguían códigos de conducta que juzgaban desactualizados, son los mismos que cuestionaban a las interpretaciones de Sosa o Varela por considerarlas impostaciones de "algo que en realidad no son", encarnaciones de "personajes" de otro tiempo y contexto. Vulgares, falsos, imitaciones. Utilizaban las mismas valoraciones para descalificar cantantes, músicos y milongueros: "payasos", “impostaciones”. Detrás de esos juicios encontramos, a nuestro modo de ver, la misma creencia según la cual el Tango, el "auténtico" Tango debe ser actualizable, y la contrapartida de que toda emulación del pasado es una falsificación. En ese juicio muchas veces oponían valores como la creatividad o la "calidad" estética a estas impostaciones.

Tampoco parece casual esta correspondencia.

\subsection{Interpretación, apropiación e interés}

Lo que sigue a continuación son algunas hipótesis y reflexiones orientadas a comprender esas correspondencias antes descriptas. Como toda abducción, no es más que el ejercicio creativo ante la evidencia que pone a prueba a los modelos mentales preexistentes.

Lo primero que derivamos de esta investigación es que si pretendemos comprender por qué una pieza musical es considerada por un grupo de sujetos como un tango "auténtico" y no como una impostación, no podemos quedarnos en la descripción del prototipo de tango. El prototipo no fija los límites, solamente nos dice cuál es el ejemplo mejor. Luego 
hará falta un intérprete que determine cuánto puede un caso alejarse de ese prototipo, en qué elementos puede ser diferente y cuán diferente puede ser.

Esa similitud o distancia se juzga en base al reconocimiento de ciertos rasgos que serían más esenciales (Violi, 2001). En algunos casos la presencia de uno solo de esos rasgos parecía ser suficiente para incluir el caso en la categoría (como la pertenencia a un repertorio instituido en el caso de los tradicionalistas). En otros parecía ser la conjunción de varios rasgos, como si adicionaran cada uno de ellos más "tanguitud". Como fuere, la determinación de cuán necesarios son ciertos rasgos es algo que se realiza en base a inferencias fundadas en los saberes previamente incorporados. Los prototipos forman parte de esos saberes, pero no son los únicos. Otras creencias vienen a ocupar el lugar de premisas complementarias de las que se sirven los intérpretes, especialmente cuando los enfrentamos a casos menos prototípicos. Y en esa tarea, las creencias en torno a los que el Tango es, parecen jugar un papel importante.

Aquí sería pertinente aclarar que bajo ningún concepto pretendemos decir que las creencias que albergan los milongueros guardan, necesariamente, total coherencia. Lo que queremos decir es que ellos pretenden que guarden coherencia lo cual, enfrentados a la tarea de emitir juicios sobre el tango, podría empujarlos a armonizarlas. Esa pretensión de coherencia entre las creencias sería lo que hace que éstas tiendan a articularse orientadas más o menos en las mismas direcciones. Pero eso no sería tan interesante si no notáramos que esas creencias en las que se fundan los juicios interpretativos están, no casualmente, en sintonía con sus intereses.

Las prácticas de apropiación del tango son la arena en la que se exponen las competencias y los recursos de los milongueros, competencias y recursos que están cargados de valor y impactan en el lugar social de cada cual en el circuito milonguero ${ }^{36}$. Por eso no sería de extrañar

\footnotetext{
${ }^{36} \mathrm{Al}$ respecto cabe destacar que la semiótica históricamente ha hecho un uso de la noción de competencia que no toma en cuesta esta dimensión (Díaz, 2011), básicamente porque asumen una noción de comunidad de intérpretes homogénea y sin disputa.
} 
que prefieran creer en aquellas definiciones de lo que el Tango es, que legitiman y dan valor a sus propios recursos por sobre los de otros. Con esto no queremos decir que cada milonguero individualmente elija creer en lo que más le place, puesto que si fuera así la comunicación y, todavía más, la comunidad misma, serían inviables. Lo que decimos es que en comunidades donde las definiciones principales de lo que determinados signos son y representan están disputadas por distintos paradigmas discursivos, los intérpretes estarían inclinados a adherir a aquel paradigma cuyas normas de apropiación se adaptan mejor a sus intereses ${ }^{37}$.

Queremos destacar, en definitiva, que estas creencias no son inocentes. Afirmar que el tango tiene una esencia fija que no debe ser transgredida tiene efectos directos en la legitimación de determinadas prácticas de apropiación por sobre otras. Prácticas de apropiación que requieren determinados recursos que se encuentran distribuidos de manera desigual, de modo que estas creencias tienen impacto directo en el valor de los recursos que disponen los distintos usuarios y, en definitiva, en el lugar social en el que esos recursos los colocan.

Y que son esas mismas creencias las que los asisten en sus juicios interpretativos toda vez que funcionan como premisas de sus procesos inferenciales.

$\mathrm{Y}$ es aquí donde, nos parece, sería pertinente revisar los enfoques semióticos tradicionales que se desprenden rápidamente de los usos de los signos en favor de la interpretación, como si ambas instancias no tuvieran vínculos pertinentes para nuestra disciplina.

Todavía más, nos obligaría a considerar la posibilidad de que, tal vez, los intereses propios de los usuarios de los signos tengan influencia en las creencias que adoptan $y$, con ello, en las interpretaciones que realizan. Los resultados de esta investigación nos señalan, precisamente,

\footnotetext{
${ }^{37}$ Peirce reconocía la existencia de un método a priori de fijación de las creencias en el que el principio rector era el propio gusto (CP 5.382). Daba como ejemplo a Platón, que creía que las distancias entre los planetas eran proporcionales a las longitudes de acordes armoniosos sólo porque encontraba esta teoría agradable a la razón. Algo similar podría estar ocurriendo aquí, donde por gusto, podríamos bien pensar conveniencia.
} 
esa dirección. Y aunque las correspondencias no nos autorizan a derivar causalidades, sí nos obligan a poner en duda las casualidades.

Nos está indicando la necesidad de hacer abordajes que consideren no solamente los aspectos propiamente cognitivos de los procesos interpretativos, sino la dimensión sociosemiótica de las prácticas sociales a través de las cuales se produce la experiencia. Esa misma experiencia de la que los intérpretes derivan no sólo las creencias más generales en torno a lo que una música es o significa, sino los prototipos interpretativos que utilizan para reconocer un conjunto de sonidos como un tango y no como un bolero.

La semiótica cognitiva bien reconoce que es la experiencia ya sea directa o discursiva - la fuente de donde proceden los saberes y competencias puestos en juego a la hora de interpretar los signos. Lo que ha pasado por alto, a nuestro entender, es que esa experiencia está jalonada por luchas, intereses y apuestas de sentido de parte de agentes que no son pasivos receptores de los signos.

En definitiva, que:

Si el signo es una arena de luchas (Voloshinov, 1992)

Y los interpretantes son signos (CP 2.228),

luego, los interpretantes son una arena de luchas.

\section{REFERENCIAS BIBLIOGRÁFICAS}

BOURDIEU, P. (1991). El sentido práctico. Madrid: Taurus. (1995). Respuestas. México: Grijalbo.

CAROZZI, M. J. (2011). "Ni tan pasionales ni tan decentes: tras las huellas de la liviandad en las clases de tango milonguero y las milongas céntricas porteñas". En Las palabras y los pasos: Etnografías de la danza de la ciudad, M. J. Carozzi (coord.), 223-263. Buenos Aires: Ed. Gorla. 
COSTA, R. y MOZEJKO, T. (2002). "Producción discursiva: diversidad de sujetos". En Lugares del decir, T. Mozejko y R. Costa (comps.), 13-22. Rosario: Homo Sapiens. (2007). "Introducción". En Lugares del decir 2, T. Mozejko y R. Costa (comps.). Rosario: Homo Sapiens.

DIAZ, C. (2009). Variaciones sobre el ser nacional. Una aproximación sociodiscursiva al folklore argentino. Córdoba: Recovecos. (2011). "Música popular, investigación y valor". En Música popular y juicios de valor: una reflexión desde América Latina, J. F. Sans y R. López Cano (coords.). Caracas: CELARG.

(2013). "Recepción y apropiación de músicas populares: Dispositivos de enunciación, lugares sociales e identidades". El Oído Pensante 1.2. Disponible en línea: http://ppct.caicyt.gov.ar/index.php/ oidopensante [12/12/2013].

ECO, U. (1987). Lector in fabula. Barcelona: Lumen.

(1992). Los límites de la interpretación. Barcelona: Lumen. (1999). Kant y el ornitorrinco. Barcelona: Lumen

GUERRERO, J. (2012). "El género musical en la música popular: algunos problemas para su caracterización”. TRANS-Revista Transcultural de Música 16. Disponible en línea: https://www.sibetrans.com/ trans/public/docs/trans_16_09.pdf [21/03/2018].

GIBSON, J. (2015). The ecological approach to visual perception. New York: Psychology Press [Versión Kindle].

GLASSER, B. \& STRAUSS, A. (1967). The Discovery of Grounded Theory: Strategies for Qualitative Research. Nueva York: Aldine.

KALIMAN, R. y CHEIN, D. (2014). Sociología de las identidades. Villa María: Eduvim (E-book).

LISKA, M. M. (2016). "Las transgresiones del tango electrónico: condiciones sociales contemporáneas y valoraciones estéticas en los bordes del tango". Revista Musical Chilena 70.225. Disponible en línea: http://dx.doi.org/10.4067/S0716-27902016000100002 [11/04/2018]. 
LÓPEZ CANO, R. (2004a). "Elementos para el estudio semiótico de la cognición musical. Teorías cognitivas, esquemas, tipos cognitivos y procesos de categorización". En Géneros, estilo y competencia en la semiótica musical cognitiva actual. Montevideo: Escuela Universitaria de la Música de Uruguay. Disponible en línea: http:// www.eumus.edu.uy/amus/lopezcano/articulo2.html [20/12/2014].

(2004b). "Favor de no tocar el género: géneros, estilo y competencia en la semiótica musical cognitiva actual”. En Voces e imágenes en la etnomusicología actual. Actas del VII Congreso de la SibE, J. Martí y S. Martínez (eds.), 325-337. Madrid: Ministerio de Cultura. (2011). "Música, mente y cuerpo. De la semiótica de la representación a una semiología de la performatividad". En De cerca, de lejos. Miradas actuales en musicología de/sobre América Latina, M. Fornaro (ed.). Montevideo: Universidad de la República. Disponible en: http://lopezcano.org/Articulos/2011.perform.pdf [11/12/2010].

LORENZO CADARSO, P. (1995). "Principales teorías sobre el conflicto social". Norba Revista de Historia 15, 237-254. Disponible en línea: https://dialnet.unirioja.es/descarga/articulo/241031.pdf [11/04/2018].

MONTES, M. de los A. (2011). "Interpretación y prácticas sociales en la recepción del tango". AdVersus VIII.21, 125-148. Disponible en línea: www.adversus.org/indice/nro-21/articulos/06-VIII-21.pdf [27/03/2018].

(2015). "Paradigmas discursivos, disputas por el sentido y normas de apropiación en la recepción del tango”. AdVersuS XII.29, 91-114. Disponible en línea: www.adversus.org/indice/nro-29/articulos/ XII2905.pdf [27/03/2018].

(2014). "Operaciones interpretativas y prácticas de apropiación de signos con materialidad múltiple en la recepción del tango". AdVersuS XI.27, 32-57. Disponible en línea: http://www.adversus. org/indice/nro-27/articulos/XI2703.pdf [18/04/2012].

(2016). "Dime que tango quieres y te diré quién eres". La Trama de la 
Comunicacion 20. Disponible en linea: http://www.latrama.fcpolit. unr.edu.ar/index.php/trama/article/view/567/422 [04/12/2016].

PAOLUCCI, C. (2011). “The 'External Mind': Semiotics, Pragmatism, Extended Mind and Distributed Cognition". VS Quaderni di studi semiotici, 112-113 [Kindle Edition].

(2013). Strutturalismo e interpretazione. Ambizioni per una semiotica “minore". Milano: Bompiani [Kindle version].

PEIRCE C. S. (1931-1958). Collected Papers, C. Hartshorne, P. Weiss \& A. W. Burks (eds), vols. 1-8.. Cambridge, Ma: Harvard University Press.

PELINSKI, R. (2005). “Corporeidad y experiencia musical”. TRANSRevista Transcultural de música 9. Disponible en: http://www. sibetrans.com/trans/a177/corporeidad-y-experiencia-musical [09/11/2010].

PUJOL, S. (1999). Historia del baile. De la milonga a la disco. Buenos Aires: Emecé.

ROSCH, E. (1978). "Principles of categorization". En Cognition and categoritation, E. Roach \& B. Lloyd (eds.), 27-48. New Jersey: Lawrence Erlbaum Associates Publishers.

VIOLI, P. (2001). Significato ed esperienza. Milano: Bompiani.

VOLOSHINOV, V. (1992). El marxismo y la filosofía del lenguaje. Madrid: Alianza Editorial.

WILLIAMS, R. (1980). Marxismo y literatura. Barcelona: Península.

Recibido el 20 de abril de 2018.

Aceptado el 25 de junio de 2018. 